\title{
Effectiveness of Character Strengths Intervention Model on Overall Academic Performance and Performance in English and Maths among Middle School Children
}

\author{
Mrs. Mamatha $\mathrm{K}^{1 *}$, Dr. Sumita Chowhan ${ }^{2}$ \\ ${ }^{1}$ Research Scholar, Dept. of Psychology, Jain University, Bangalore, India \\ ${ }^{2}$ Assistant Professor \& Doctoral Guide, PG Department of Psychology, Jain University, Bangalore, India
}

\author{
DOI: $10.36348 /$ jaep.2020.v04i11.010 \\ | Received: 12.11.2020 | Accepted: 23.11.2020 | Published: 25.11 .2020
}

*Corresponding author: Mrs. Mamatha K

\section{Abstract}

Academic performance has a greater influence on many aspects in a child's life. Academic achievement has a greater influence on self-esteem, motivation and perseverance among students. Academic performance assesses the thinking, absorbing and information processing of students. Experts in the field of education system have consistently tried to make it a better place for learning. Research works in the field is running parallel in implementing new ideas to have an effective learning practice. The present study focused on developing intervention model using character strengths from Positive Psychology to identify the effectiveness of intervention model on overall academic performance and performance in English and Maths among middle school children. Pre-Post analysis was executed on the control and the experimental group. Results show that there is significant difference in the Effectiveness of Character Strength Intervention Model on the overall academic performance and performance in English and Maths among middle school children.

Keywords: Character Strengths Intervention Model, Academic Performance, English, Maths.

Copyright $\odot$ (2020 The Author(s): This is an open-access article distributed under the terms of the Creative Commons Attribution 4.0 International License (CC BY-NC 4.0) which permits unrestricted use, distribution, and reproduction in any medium for non-commercial use provided the original author and source are credited.

\section{INTRODUCTION}

Academic performance is of major concern to all educators, parents and students [1]. Children are widely affected by the concept called academic performance. Children, feel to be judged or assessed through academic performance. Their level of thinking, absorbing and processing information is assessed through academic performance [2]. Academic performance has a greater influence on many aspects in a child's life. Academic achievement has a greater influence on self-esteem, motivation and perseverance among students. Academic performance of children in each subject would differ. Interest, teaching style, learning style, difficulty level are some of the influencing factors in bringing difference in performance.

Character Strengths, given by positive psychology is a way to identify the strengths among individuals and make it a conscious practice for the betterment and well-being of human life. Positive psychology focuses on factors that enable children and adolescents to grow [3]. Having knowledge about something positive in an individual would increase self- efficacy to deal with challenges confidently and adaptively. Strengths can be used to build optimal states such as flow. Seligman proposed that one way to build flow is through identifying character strengths and help people to find their opportunities to use these strengths more often [4]. This use of strengths would have holistic growth and development. Researchers have been working on bringing connections between the use of character strengths and positive outcomes.

\section{Need of the Study}

Teaching character strengths and identifying its effectiveness would be possible through intervention models. Character strengths have shown its positive effect on well-being among children. Character strengths could help children to become more focused and aware about their actions or performances. Intervention models can be designed for improvement of specific behaviour. Present study focused to develop character strengths intervention model and study the effectiveness of the model on overall academic performance and performance in English and Maths among middle school children. The character strength intervention model shows the importance of its 
effectiveness in improving academic performance among middle school children.

\section{REVIEW OF LITERATURE}

Reviews of literature acts as the support system for the further research and also helps to build better research activity to make the society a better place of living. Literature reviews updates and upgrades the research field. Jayanthi, et al. [5] studied the factors contributing to academic performance of students. Results showed that factors such as gender, nationality, co-curricular activities and also a basic interest to pursue higher degrees influenced academic performance. Use of previous years questions papers for study has shown an improvement in student's academic performance. Another study by Tella [6] showed the impact of motivation on student's academic achievement and learning outcomes in mathematics among secondary school students in Nigeria. Results reveal that gender difference were significant when impact of motivation on academic achievement was compared to male and female students. There was a significant difference seen between motivation and academic performance. Study by Rashid et al. [7] on assessment of character Strengths on children and adolescents showed that Signature Strengths improved social skills and academic performance of children. Teachers reported about the improvement from pre to post intervention level. Parents also reported that the problem behaviour improved from pre to post intervention level. The most endorsed Character Strengths were zest, love, hope, curiosity, and honesty, appreciation of beauty and excellence and forgiveness. Linkins, et al. [8] tried to understand the framework of education through the lens of Strengths. The study shows that character education approaches has been successful in inculcating social norms and expectations. Researches on character Strengths based classroom interventions have shown positive outcomes with relation to emotions, engagement, relationships and accomplishments.

\section{METHODOLOGY}

\section{Research Question}

- What is the Effectiveness of Character Strengths Intervention Model on Overall Academic Performance among middle school children?

- What is the Effectiveness of Character Strengths Intervention Model on Performance in English among middle school children?

- What is the Effectiveness of Character Strengths Intervention Model on Performance in Maths among middle school children?

\section{OBJECTIVE}

- To study the Effectiveness of Character Strengths Intervention Model on Overall Academic Performance among middle school children.
- To study the Effectiveness of Character Strengths Intervention Model on Performance in English among middle school children.

- To study the Effectiveness of Character Strengths Intervention Model on Performance in Maths among middle school children.

\section{HYPOTHESIS}

H0: There is no significant difference in the Effectiveness of Character Strengths Intervention Model on Overall Academic Performance among middle school children.

H1: There is no significant difference in the Effectiveness of Character Strengths Intervention Model on Performance in English among middle school children.

H2: There is no significant difference in the Effectiveness of Character Strengths Intervention Model on Performance in Maths among middle school children.

\section{Operational Definitions}

- Academic Performance: Academic performance is the outcome of education, the extent to which a student, teacher and institution has achieved their educational goals.

- Character Strengths: 24 character strengths developed by Christopher Peterson and Martin Seligman 2004 is an attempt to provide a theoretical framework to assist in developing practical applications for Positive Psychology. According to Peterson and Seligman [9] character strengths are ubiquitous traits which are valued in their own right and not necessarily tied to tangible outcomes. Character strengths do not diminish others; rather they elevate those who witness the strength expression, producing admiration not jealousy.

- Intervention Model: The general design describing the strategy in which interventions will be assigned to participants in a clinical study.

\section{RESEARCH DESIGN}

Pre and post experimental \& control research design was used where people being studied are randomly allocated one or other of the different treatments under study.

\section{Inclusion Criteria}

- Samples from CBSE Board were part of the study.

- Samples from middle school were part of the study.

- Samples residing in Bangalore were part of the study.

\section{Exclusion Criteria}

- Samples from residential/boarding school were excluded.

- Samples diagnosed with intellectual disability/learning disability were excluded. 


\section{Sampling Technique}

- Convenient and random sampling technique was used for the study.

\section{Sample}

- Samples within the age group of 11-14 yrs were considered for the study.

- Control Group $(\mathrm{N}=30)$

- Experimental group $(\mathrm{N}=30)$

\section{Tools of Assessment}

- Character Strengths Intervention Model: developed by the scholars for the study.

- Overall Academic performance and Performances in English and Maths were collected by seeking permission from the school authorities.

\section{Procedure}

Research scholars explained the objective of the study to the school authorities. Consent was taken from parents of middle school children to be part of the study. Pre-Post experimental design was used for the study. 30 samples each for control and the experimental group were allotted respectively. The study was executed in Three Phases.

Phase I: Pre Test: Overall Academic performance, performance in English and Maths of the samples (control \& experimental) was recorded. Control group were not part of the Character Strengths Intervention Model. Their academic performance was recorded for the further analysis.

Phase II: Character Strengths Intervention Model: The Character Strengths Intervention Model was executed on the experimental group. Out of 24 Character Strengths from Positive Psychology Humility, Love of Learning, Gratitude, Perseverance, Social Intelligence, Optimism and Curiosity were selected for the model based on Review of Literature. The experimental group underwent the Character Strengths Intervention Model. Each Character Strength was taken up for each session. Overall 7 sessions was designed. Each session was executed for 30 minutes. Introduction, activities, audio-visuals and summing up of the Character Strength was the method followed in each session. As conclusion on the last day of the session, summary session for 10 minutes was facilitated to interact with the experimental group and identify their opinion and impression about the Intervention Model.

Phase III: Post Test: Overall Academic performance, performance in English and Maths of the samples (control \& experimental) was recorded. The control group was not part of the intervention model for the purpose of the study. But as a part of ethical consideration, the control group should have all the benefits of positive effect of Intervention Model. The scholars facilitated intervention model on the control group after the completion of the study

\section{ANALYSIS OF DATA}

Paired sample 't' test was executed for data analysis using statistical software SPSS version 20 .

\section{RESULTS \& DISCUSSION}

Research works have always attempted in making education system better. Upgrading and updating is a very crucial factor. A holistic growth of the school would focus on the overall development of children, who are the future of Nation. A study by White \& Waters [9] explored a case study on "The Good School". The study used Peterson's Strengthsbased approach with students. 12 grade students from Australia were part of the study. The study describes five Character Strengths initiatives. Four of the initiatives are integrated in school experiences such as English Curriculum, school sport, student leadership and counseling. The fifth initiative introduced new program called Positive Education Curriculum. The results of the study show the importance of practice of character strengths and making it a part of curriculum. Intervention Models have been a backbone in executing all the plans for the curriculum. The present study has focused on developing Character Strengths Intervention Model which would have a positive impact on academic performance among children. Its not only the overall performance, but can be focused on specific subjects like English and Maths taken for the study. Effectiveness of Character Strengths Intervention Model would give suggestions in implementing it as daily curriculum and work towards the holistic development of children.

The results and analysis of the present study has been presented below.

Table-1: Shows the mean, Std. Deviation, $t$ value and the significance of the control and experimental group for the pre and post for Overall Academic Performance

\begin{tabular}{|l|l|l|l|l|l|}
\hline \multicolumn{2}{|l|}{ Paired Samples Statistics } \\
\hline \multicolumn{2}{|l|}{} & Mean & $\mathbf{N}$ & Std. Deviation & Std. Error Mean \\
\hline \multirow{2}{*}{ Pair 1 } & Pre CG Overall Acp & 69.17 & 30 & 14.106 & 2.575 \\
\cline { 2 - 6 } & Post CG Overall Acp & 70.47 & 30 & 12.937 & 2.362 \\
\hline \multirow{2}{*}{ Pair 2 } & Pre EG Overall Acp & 67.63 & 30 & 13.887 & 2.535 \\
\cline { 2 - 6 } & Post EG Overall Acp & 69.67 & 30 & 13.867 & 2.532 \\
\hline
\end{tabular}


Table-1a: Shows the significance value of the paired sample test

\begin{tabular}{|l|l|l|l|l|l|l|}
\hline \multicolumn{2}{|l|}{ Paired Sample Test } & Mean & Std. Deviation & Std. Error Mean & t & Sig. (2-tailed) \\
\hline Academic Performance & & & & & \\
\cline { 2 - 9 } & Control Group & -1.300 & 2.667 & .487 & -2.670 & .012 \\
\hline
\end{tabular}

H0 - The first null hypothesis states that "There is no significant difference in the Effectiveness of Character Strengths Intervention Model on Overall Academic Performance among middle school children". The controlled group has less academic performance in pretest $(69.17 \pm 14.106)$ than in posttest $(70.47 \pm 12.937)$. The $\mathrm{t}$ value is significant at 0.05 level $(\mathrm{df}=29, \mathrm{t}=$ $2.670, \mathrm{p}=.012)$. The experimental group has less academic performance in pretest $(67.63 \pm 13.887)$ than in posttest $(69.67 \pm 13.867)$. The $t$ value is significant at 0.01 level $(\mathrm{df}=29, \mathrm{t}=-3.913, \mathrm{p}=.001)$. Therefore, In the case of experimental group, $\mathrm{p}<0.01$, the null hypothesis is rejected and alternate hypothesis is accepted. "There is significant difference in the Effectiveness of Character Strength Intervention Model on Overall Academic Performance among middle school children". Although the controlled group show the difference, they are significant at 0.05 level whereas the experimental group shows the significance at 0.01 level. Henceforth the results indicate the Character Strengths Intervention Model shows its impact on overall academic performance among middle school children.

Table-2: Shows the mean, Std. Deviation, $t$ value and the significance of the control and experimental group for the pre and post for Performance in English

\begin{tabular}{|l|l|l|l|l|l|}
\hline \multicolumn{2}{|l|}{ Paired Samples Statistics } & Mean & N & Std. Deviation & Std. Error Mean \\
\hline \multirow{2}{*}{ Pair 1} & Pre CG Acp English & 70.23 & 30 & 14.175 & 2.588 \\
\cline { 2 - 6 } & Post CG Acp English & 70.33 & 30 & 15.334 & 2.800 \\
\hline \multirow{2}{*}{ Pair 2} & Pre EG Acp English & 65.00 & 30 & 13.716 & 2.504 \\
\cline { 2 - 6 } & Post EG Acp English & 68.43 & 30 & 12.754 & 2.329 \\
\hline
\end{tabular}

Table-2a: Shows the significance value of the paired sample test

\begin{tabular}{|l|l|l|l|l|l|l|}
\hline \multicolumn{2}{|l|}{ Paired Sample Test } & Mean & Std. Deviation & Std. Error Mean & t & Sig. (2-tailed) \\
\hline \multirow{2}{*}{ English } & Control Group & -.100 & 4.971 & .908 & -.110 & .913 \\
\cline { 2 - 8 } & Experimental Group & -3.433 & 6.867 & 1.254 & -2.739 & .010 \\
\hline
\end{tabular}

H1: The second null hypothesis states that "There is no significant difference in the Effectiveness of Character Strength Intervention Model on Performance in English among middle school children". The controlled group has less academic performance in English in pretest $(70.23 \pm 14.175)$ than in posttest $(70.33 \pm 15.334)$. The $t$ value is not significant at 0.05 level $(\mathrm{df}=29, \mathrm{t}=-.110, \mathrm{p}=.913)$. The experimental group has less academic performance in English in pretest $(65.00 \pm 13.716)$ than in posttest $(68.43 \pm 12.754)$. The $\mathrm{t}$ value is significant at 0.01 level $(\mathrm{df}=29, \mathrm{t}=-$
$2.739, \mathrm{p}=.010)$. Therefore, In the case of experimental group, $\mathrm{p}<0.01$, the null hypothesis is rejected and alternate hypothesis is accepted. "There is significant difference in the Effectiveness of Character Strength Intervention Model on Performance in English among middle school children". Results show that the control group is not significant at 0.05 level, whereas experimental group is significant at 0.01 level. Henceforth the results indicate the Character Strengths Intervention Model shows its impact on performance in English among middle school children.

Table-3: Shows the mean, Std. Deviation, $t$ value and the significance of the control and experimental group for the pre and post for Performance in Maths

\begin{tabular}{|l|l|l|l|l|l|}
\hline \multicolumn{2}{|l|}{ Paired Samples Statistics } & Mean & N & Std. Deviation & Std. Error Mean \\
\hline \multirow{2}{*}{ Pair 1 } & Pre CG Acp Maths & 66.53 & 30 & 14.381 & 2.626 \\
\cline { 2 - 6 } & Post CG Acp Maths & 67.40 & 30 & 13.158 & 2.402 \\
\hline \multirow{2}{*}{ Pair 2} & Pre EG Acp Maths & 63.23 & 30 & 13.214 & 2.412 \\
\cline { 2 - 6 } & Post EG Acp Maths & 70.67 & 30 & 12.936 & 2.362 \\
\hline
\end{tabular}


Table-3a: Shows the significance value of the paired sample test

\begin{tabular}{|l|l|l|l|l|l|l|}
\hline \multicolumn{2}{|l|}{ Paired Sample Test } & Mean & Std. Deviation & $\begin{array}{l}\text { Std. Error } \\
\text { Mean }\end{array}$ & \multicolumn{1}{|c|}{ t } & Sig. (2-tailed) \\
\hline \multirow{2}{*}{ Maths } & Control Group & -.867 & 3.471 & .634 & -1.367 & .182 \\
\cline { 3 - 8 } & Experimental Group & -7.433 & 7.569 & 1.382 & -5.379 & .000 \\
\hline
\end{tabular}

H2: The third null hypothesis states that "There is no significant difference in the Effectiveness of Character Strength Intervention Model on Performance in Maths among middle school children". The controlled group has less academic performance in Maths in pretest $(66.53 \pm 14.381)$ than in posttest $(67.40 \pm 13.158)$. The $t$ value is not significant at 0.05 level $(\mathrm{df}=29, \mathrm{t}=-1.367, \mathrm{p}=.182)$. The experimental group has less academic performance in Maths in pretest $(63.23 \pm 13.214)$ than in posttest $(70.67 \pm 12.936)$. The $\mathrm{t}$ value is significant at 0.01 level $(\mathrm{df}=29, \mathrm{t}=$ $5.379, \mathrm{p}=.000$ ). Therefore, In the case of experimental group, $\mathrm{p}<0.01$, the null hypothesis is rejected and alternate hypothesis is accepted. "There is significant difference in the Effectiveness of Character Strength Intervention Model on Performance in Maths among middle school children". Results show that the control group is not significant at 0.05 level, whereas experimental group is significant at 0.01 level. Henceforth the results indicate the Character Strengths Intervention Model shows its impact on performance in Maths among middle school children.

\section{DISCUSSION}

Results show that Intervention Model has a positive effect on overall academic performance and performance in English and Maths. The study shows that intervention model can have a positive impact on not only the overall academic performance but also with respect to specific subjects. Character Strengths play a major role in holistic development among children. Several studies have shown its impact on growth, well-being and happiness among children. The present study supports the viewpoint that academic performance can be improved by focusing on developing character strengths among children. Based on review of literature English and Maths subjects were considered for the study. Implementing Intervention Model would help children to make their learning process effective and improve their performance. It can be inferred from the results that Intervention Model would have an impact on overall academic performance and performance in English and Maths among middle school children.

The summary session of the model with the experimental group, attempted to understand the perception of samples about the model. Samples expressed that, sessions were very interesting and relaxing. Activities made the topic very interesting, and also made them understand the importance of strengths. One of the samples expressed "we would like to have many such activities in our classrooms as well", another sample told "though we knew some of them, we never thought about those in so much detail". Opinions shared by samples showed that Intervention Model was effective and samples could relate themselves to the strengths trained during sessions. Conscious practices of character strengths have greater benefits in the life of students.

\section{CONCLUSION}

The conclusion has been drawn based on the statistical analysis. Character Strengths Intervention Model has been effective on Overall Academic Performance and Performance in English and Maths.

\section{Limitations}

The study has focused only on the academic performance. Other variables like learning styles, teaching styles or learning strategies could have been part of the study to make it more effective.

\section{Suggestions}

Studies could be executed using the model with many other variables like learning strategies, character strengths, happiness, and well-being or life satisfaction.

\section{REFERENCES}

1. Felder, R. M., \& Henriques, E. R. (1995). Learning and teaching styles in foreign and second language education. Foreign language annals, 28(1), 21-31.

2. Markova, I. S., \& Berrios, G. E. (1992). The assessment of insight in clinical psychiatry: a new scale. Acta Psychiatrica Scandinavica, 86(2), 159164.

3. Park, J., An, K., Hwang, Y., Park, J. G., Noh, H. J., Kim, J. Y., ... \& Hyeon, T. (2004). Ultra-largescale syntheses of monodisperse nanocrystals. Nature materials, 3(12), 891-895.

4. Gokalp, Murat. (2013). The Effect of Students' Learning Styles to their Academic Success. Creative education. Vol. 4. No. 10. Pp- 627-632.

5. Jayanthi, P. D. K., Kempraj, V., Aurade, R. M., Venkataramanappa, R. K., Nandagopal, B., Verghese, A., \& Bruce, T. J. (2014). Specific volatile compounds from mango elicit oviposition in gravid Bactrocera dorsalis females. Journal of chemical ecology, 40(3), 259-266.

6. Tella, A. (2007). The impact of motivation on student's academic achievement and learning outcomes in mathematics among secondary school students in Nigeria. Eurasia Journal of 
Mamatha K \& Sumita Chowhan., J Adv Educ Philos, Nov, 2020; 4(11): 494-499

Mathematics, Science and Technology Education, 3(2), 149-156.

7. Rashid, M. M., Hossain, M. M., Azad, M. A. K., \& Hashem, M. A. (2013). Long term cyclic heat stress influences physiological responses and blood characteristics in indigenous sheep. Bangladesh Journal of Animal Science, 42(2), 96-100.

8. Linkins, M., Niemiec, M.R., Gillham, J., \& Mayerson, Donna. (2014). Through the lens of strength: A framework for educating the heart. The
Journal of Positive Psychology: Dedicated to furthering research and promoting good practice. DOI: $10.1080 / 17439760.2014 .888581$.

9. White, A.M., Waters, E, Lea. (2014). A case study of 'The Good School:' Examples of the use of Peterson's strengths-based approach with students. The Journal of Positive Psychology: Dedicated to furthering research and promoting good practice. DOI: 0.1080/17439760.2014.920408. 